\title{
Elective aortic and mitral valve surgery in patients over 70 years of age
}

\author{
R. CANEPA-ANSON AND R. W. EMANUEL \\ From National Heart Hospital, Westmoreland Street, London
}

SUMMARY The results of elective cardiac surgery carried out between 1970 and 1975 on 29 patients over 70 years of age are reported. Operative mortality was 10 per cent, late cardiac mortality 14 per cent, with 72 per cent survival at a mean follow-up of 38.6 months. Before operation 96 per cent were in functional classes 3 and 4 . After operation 90.5 per cent of late survivors were in functional classes 1 and 2 at a mean follow-up of 43.5 months. These results compare favourably with those in younger patients. Complication rate and length of hospital stay were unremarkable. The risks of neurological damage and of long-term anticoagulation are not increased. Emergency surgery carries a very high risk in this age group. The importance of biological youth and good left ventricular function is emphasised. For aortic stenosis at least prognosis is improved by surgery.

In 1973 the results of heart valve surgery at the National Heart Hospital in patients over 60 years of age were reported (Oh et al., 1973). After these results an increased number of elderly patients have been referred for operation and in this report we have analysed the outcome of elective cardiopulmonary bypass surgery in patients over the age of 70 .

\section{Clinical material and methods}

Between July 1970 and July 197529 patients over the age of 70 underwent open heart surgery at the National Heart Hospital and Harefield Hospital. The age range was 70 to 75 (mean 71) years. There were 20 men and 9 women. The NYHA classification of functional class (1964) was used to define effort tolerance. Before operation all except 1 patient were severely limited by cardiac symptoms to functional classes 3 or 4 (see Fig. A). All 29 patients were biologically young and though 16 patients had other medical conditions (see Table 1), these were not considered to contraindicate surgery.

Sixteen patients underwent preoperative left heart catheterisation, and in 4 this included selective coronary arteriography. Left ventricular end-diastolic pressures were recorded and ejection fractions were calculated by computerised analysis of enddiastolic and end-systolic frames of the left ventricu-

Received for publication 8 September 1978 
Table 1 Surgery in the over 70's

\begin{tabular}{ll}
\hline Additional conditions present before surgery & No. of patients \\
\hline Chronic airways obstruction & 2 \\
Gout & 1 \\
CVA (embolic from MVD) & 1 \\
Hypertension & 2 \\
Impaired cardiac conduction & 2 \\
Parkinson's disease & 1 \\
Chronic DU & 1 \\
Vertebro-basilar insufficiency & 1 \\
Diabetes mellitus & 1 \\
Intermittent claudication & 1 \\
Hashimoto's disease & 1 \\
Prostatism & 2 \\
\hline
\end{tabular}

CVA $=$ cerebrovascular accident $;$ MVD $=$ mitral valve disease $;$ $\mathrm{DU}=$ duodenal ulcer.

lar angiogram. Only normally conducted beats were analysed; post-ectopic beats were excluded.

Operative mortality was defined as death at operation or from complications before discharge. Early survivors were those who left hospital alive after operation. Late survivors were those who were alive at the final follow-up.

All patients were seen at either the National Heart Hospital or at Harefield Hospital within 1 year and in many instances more recent information was obtained from their general practitioners.

\section{Results}

Preoperative diagnoses and the operations performed are shown in Table 2. Bypass times were recorded for 17 out of 29 operations and the duration of myocardial ischaemia from aortic clamping was recorded in 6 . The bypass time varied from 33 to 136 minutes, with a mean of 64 minutes. Ischaemic time varied from 10 to 40 minutes, with a mean of 26 minutes. With 1 exception all patients whose ischaemic time exceeded 10 minutes were operated on before 1973.

\section{LEFT VENTRICULAR FUNCTION}

The left ventricular end-diastolic pressure (LVEDP) varied from 8 to $30 \mathrm{mmHg}$, with a mean of 16 $\mathrm{mmHg}$. Left ventricular ejection fractions ranged from 0.40 to 0.86 , with a mean of 0.58 . There was no obvious correlation between LVEDP and ejection fraction, and ejection fractions were well maintained despite raised end-diastolic left ventricular pressures.

\section{OPERATIVE MORTALITY}

Of the 29 patients, 3 died in hospital after operation giving an operative mortality of 10 per cent: 1 at 5 days after resection of infarcted ileum and decompression colostomy, another at 11 days trom pneumonia after prolonged ventilation, and the third at 17 days from diabetic ketoacidosis complicated by septicaemia and renal failure after an initially excellent haemodynamic recovery. One of these deaths occurred after aortic valve replacement and 2 after mitral valve replacement.

\section{POSTOPERATIVE COURSE}

Sixteen patients (55\%) had an uncomplicated postoperative course. In the remaining 13 patients (45\%) 24 complications occurred (Table 3). Apart from those associated with the operative mortality these were minor. Only 1 patient suffered intellectual impairment and/or personality change after cardiopulmonary bypass. This consisted of impairment of short-term memory with associated depression and followed aortic valve replacement with a bypass time of 50 minutes. There were no focal neurological lesions.

The average postoperative hospital stay was 19 days (range 11 to 35 ). Of 26 survivors, 9 (34\%) were discharged home within 14 days of operation.

\section{LATE DEATHS}

There were 5 late deaths, 4 cardiac and 1 resulting from other causes, giving a late cardiac mortality of 13.8 per cent and a late non-cardiac mortality of 3.4

Table 2 Preoperative diagnoses and operative treatment

\begin{tabular}{|c|c|c|}
\hline No. of patients & Diagnosis & Operations \\
\hline 16 & Calcific aortic stenosis & Aortic valve replacement $\times 18\left\{\begin{array}{l}9 \text { Starr-Edwards } \\
8 \text { Homograft }\end{array}\right.$ \\
\hline 2 & Aortic regurgitation & (1 Björk-Shiley \\
\hline 1 & $\begin{array}{l}\text { Aortic regurgitation after previous aortic } \\
\text { dissection }\end{array}$ & Resuspension of aortic valve and dacron replacement of ascending aorta \\
\hline $\begin{array}{l}1 \\
1 \\
4\end{array}$ & $\begin{array}{l}\text { Aortic and mitral stenosis } \\
\text { Mixed aortic valve disease and mitral stenosis } \\
\text { Mitral regurgitation }\end{array}$ & $\begin{array}{l}\text { Aortic valve replacement and } \\
\text { mitral valvotomy } \times 2 \\
\text { Mitral valve repair } \times 1\end{array} \quad\left\{\begin{array}{l}1 \text { Starr-Edwards } \\
1 \text { Björk-Shiley }\end{array}\right.$ \\
\hline 3 & Mixed mitral valve disease & Mitral valve replacement $\times 6 \quad \begin{cases}3 & \text { Starr-Edwards } \\
2 & \text { Inverted homografts } \\
1 & \text { Braunwald-Cutter }\end{cases}$ \\
\hline 1 & Mitral stenosis & Mitral valvotomy \\
\hline
\end{tabular}

*The mean aortic valve gradient in 12 patients who were investigated was $90 \mathrm{mmHg}$, with a range of 50 to $130 \mathrm{mmHg}$. 
Table 3 Surgery in over 70's

\begin{tabular}{|c|c|}
\hline Postoperative complications & $\begin{array}{l}\text { No. of patients } \\
\text { having each } \\
\text { complication }\end{array}$ \\
\hline $\begin{array}{l}\text { Atrial fibrillation } \\
\text { Temporary pacing } \\
\text { Ventricular tachycardia } \\
\text { Ventricular fibrillation } \\
\text { Pulmonary collapse } \\
\text { Pneumonia† } \\
\text { Pneumothorax } \\
\text { Ventilatory failure† } \\
\text { Reoperation for haemorrhage } \\
\text { Diabetic comat } \\
\text { Transient confusional state } \\
\text { Small bowel infarction } \dagger \\
\text { Septicaemia and renal failure } \\
\text { Total complications }\end{array}$ & $\begin{array}{r}5 \\
4 \\
1 \\
5 \\
2 \\
1 \\
1 \\
1 \\
1 \\
1 \\
1 \\
1 \\
24\end{array}$ \\
\hline
\end{tabular}

tSignifies major causes of death.

9 of these complications occurred in 2 patients who were hospital deaths.

16 out of 29 patients had an entirely uncomplicated postoperative course.

per cent. The postoperative survival in the 5 who died varied from 3 to 27 months, mean 19 months, while that of the late survivors ranged from 20 to 80 months, mean 43.5 months. Mean survival for all operative survivors was 38.6 months. Of 4 patients who died from cardiac causes during follow-up, 3 benefited initially from their operation. One patient was active and asymptomatic after homograft aortic valve replacement until he died suddenly with chest pain 21 months after operation. Another patient improved from class 3 to class 2 for 1 year after aortic valve replacement, then he deteriorated and died 27 months after operation from progressive impairment of left ventricular function. The third patient improved from class 3 to class 2 for 6 months before developing mitral regurgitation around his Starr-Edwards prosthesis which caused severe haemolytic anaemia (haemoglobin $8.0 \mathrm{~g}$ ). He was not referred back to the National Heart Hospital and died of pneumonia at 21 months. One patient who had severe preoperative impairment of left ventricular function derived no benefit from mitral valve replacement and died 12 months after operation. The other death occurred in a patient who had already improved from class 3 to class 2 and had significant reduction in heart size before her death 3 months after Starr-Edwards aortic valve replacement and mitral valvotomy. The cause of death is unknown.

\section{CHANGES IN EFFORT TOLERANCE AND} SYMPTOMS

The change in symptoms and functional class after operation in the 21 late survivors at a mean followup time of 43.5 months is shown in Fig. A and B.

Before operation all patients except 1 were so severely incapacitated by either angina or effort dyspnoea or a combination of the two, that 96 per cent were in functional class 3 or 4 (Fig. A). The exception was a man with severe aortic regurgitation from a previous aortic dissection who had minimal symptoms (functional class 2). Of the 21 late surviviors at a mean follow-up time of $\mathbf{4 3 . 5}$ months, $12(57 \%)$ were in functional class 1 and $7(33.5 \%)$ in class 2 . Only 2 patients $(9.5 \%)$ were in class 3 . One had been in class 4 before operation, the other initially improved to class 1 but later deteriorated because of effort dyspnoea and intermittent claudication, which was a new symptom.

Comparison of pre- and postoperative symptoms shows a similar improvement. The reduction of angina from 41.5 to 4 per cent was entirely the result of relief of severe aortic stenosis. No patient who underwent aortic valve replacement had additional coronary bypass grafts. At first sight the reduction in the incidence of dyspnoea from 90 per cent to 39 per cent was less dramatic. However, among those patients who had residual dyspnoea 75 per cent were in functional class 2 while before operation 88 per cent had been in class 3 or 4 . The single late survivor with syncope developed Adams-Stokes attacks caused by complete heart block 32 months after aortic valve replacement for calcific aortic stenosis. Since implantation of a permanent pacemaker there have been no further attacks.

HEART FAILURE AND MAINTENANCE THERAPY Only 1 of 21 late survivors showed evidence of heart failure whereas preoperatively 23 out of 29 patients had clinical and radiological evidence of failure. No antifailure therapy was required for 9 of the 21 late survivors, 4 were taking digoxin, 1 diuretics, and only 6 required a combination of both digoxin and diuretics.

Sixteen patients had valve replacement with a mechanical prosthesis and required long term anticoagulation. During a follow-up ranging from 3 to 80 months (mean 38.6 months), there were no complications from anticoagulation treatment and no embolic events. None of these patients was significantly hypertensive before or after operation.

\section{Discussion}

The life expectancy for healthy 70-year-old men and women has recently been quoted as 10 and 12 years, respectively (British Medical fournal, 1976). Reviewing the 'natural history' of patients of all age groups who died from aortic stenosis, Ross and Braunwald (1968) found the mean survival after the onset of symptoms was 3 years, 80 per cent of deaths occurring within 4 years. Similar observations were 
made by Frank and Ross (1967), who found an 83 per cent mortality in 5 years in a prospective study of 12 patients treated medically after investigation had shown an aortic valve gradient of at least 50 mmHg. Thus symptomatic aortic valve disease may severely curtail life expectancy in otherwise fit 70year-old patients. In this series survival for patients with aortic stenosis was 86 per cent $(14 / 16)$, at a mean follow-up time of 43.5 months. Thus the prognosis of this condition is improved by surgery even in this age group.

The overall results of this series (hospital mortality $10 \%$ and late cardiac mortality $14 \%$ with a mean follow up period of 41 months) were similar to those of Oh et al. (1973) $(18 \%$ and $11 \%$ in 20 months, respectively), even though their patients were younger (85 [74.5\%] between 60 and 64 years and only $2[1.8 \%]$ over 70 ), and less severely disabled before operation $(50 \%$ in class 1 or 2 as compared with $93 \%$ in class 3 or 4 ). The probable reasons for this improvement are in part advances in cardiac surgery and postoperative care and in part stricter selection in terms of biological age and preoperative ventricular function.

Previous reports of cardiac surgery in the elderly have either dated from the early days of open heart surgery or dealt mainly with patients less than 70 years of age or have had only short periods of followup. These include: Austen et al. (1970) for aortic valve disease, Guthrie et al. (1972) for valve disease, Barnhorst et al. (1974) and Quinlan et al. (1975) for valve disease and coronary artery surgery, and Asho et al. (1973) and Meyer et al. (1975) predominantly for coronary artery surgery. These series are summarised in Table 4. The higher operative mortality reported by Austen et al. (1970) and Guthrie et al. (1972) probably reflects the early date of these 2 reports. Our operative mortality of 10 per cent was similar to that of the other series which varied from 9 to $15 \cdot 7$ per cent (see Table 4 ).

Isolated aortic valve replacement carried the lowest operative risk for all patients undergoing valve replacement. The mortality was 5.3 per cent in the present series, 10.6 per cent from Barnhorst et al. (1974), and 16 per cent from Quinlan et al. (1975). Mitral valve replacement carried a higher risk which varied from a mortality of 9 per cent (Quinlan et al., 1975) to 20 per cent (Barnhorst et al., 1974) and 25 per cent in the present series. For coronary artery surgery alone operative mortalities of 9 per cent and 12 per cent were reported for the larger series by Ashor et al. (1973) and Meyer et al. (1975), while Quinlan et al. (1975) and Barnhorst et al. (1974) reported no mortality in 12 patients and 3.7 per cent in 27 patients.

Only Quinlan et al. (1975) gave results of emergency surgery in elderly patients. This was defined as surgery which had to be carried out within 24 hours of the initial assessment of the patient. In a mixed group of 20 patients whose emergency operations included aortic valve replacement (7), coronary bypass grafts (4), resection of left ventricu-

Table 4 Synopsis of comparable quoted series

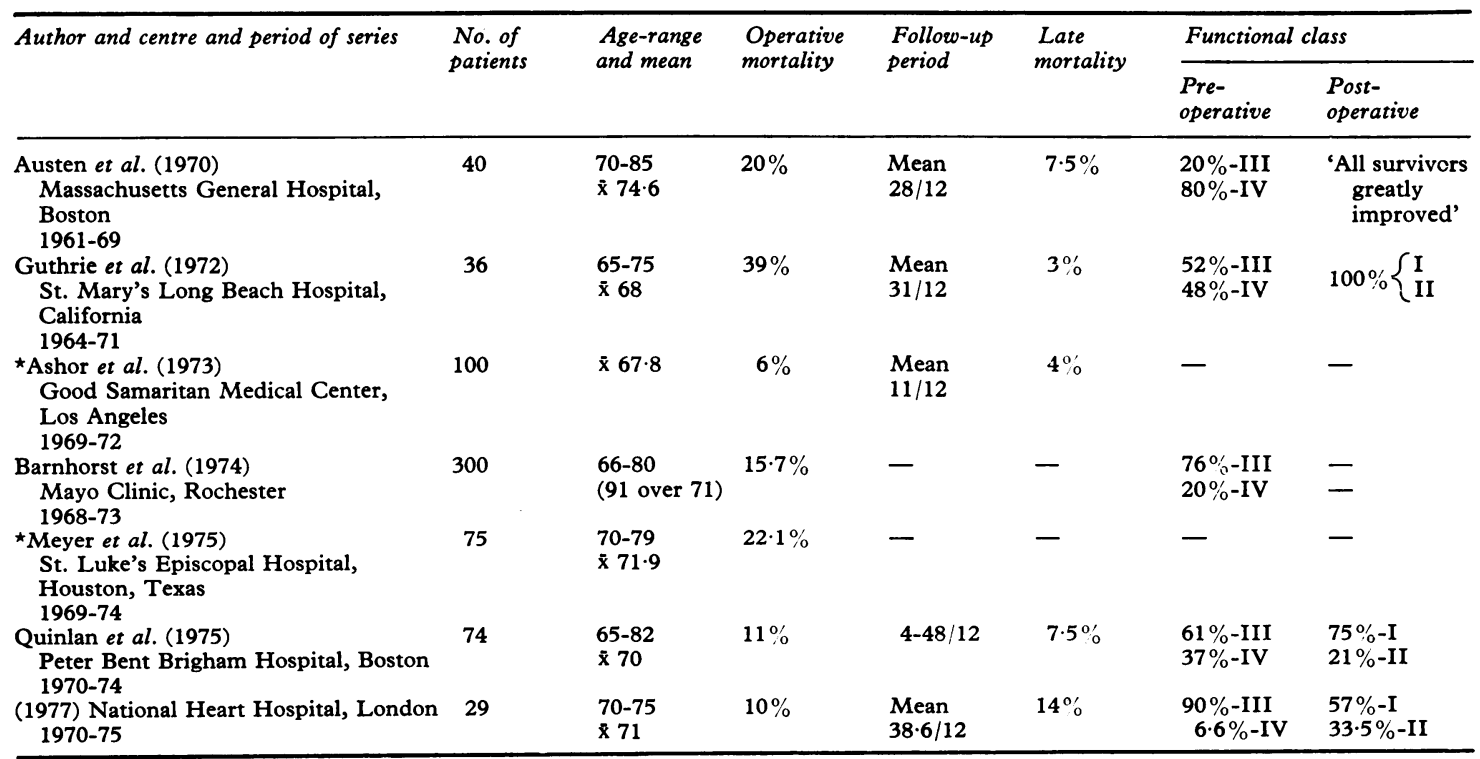

Predominantly coronary artery surgery. 
lar aneurysm (4), and acute aortic dissection (4), the mortality was 40 per cent.

Although not included in this report 8 patients over 70 underwent emergency surgery at Harefield Hospital during the period under review with an operative mortality of 75 per cent. These patients were critically ill with severe lesions. Two had mitral valve disease ( 1 with active endocarditis), 1 had critical aortic stenosis, 2 had postinfarction ventricular septal defects ( 1 survivor), 2 had acute aortic dissection (1 survivor), and 1 had coronary disease and mitral regurgitation with severe angina and left ventricular failure. These results emphasise the comments of Quinlan et al. (1975) on the importance of avoiding emergency cardiac surgery in patients over 70 whenever possible.

The question of the place of additional coronary bypass surgery in elderly patients undergoing valve replacement remains unsolved. Barnhorst et al. (1974) found that the mortality of patients undergoing aortic valve surgery and coronary bypass surgery was twice that of aortic valve replacement alone, being 22 per cent compared with 10.6 per cent. Similarly, Meyer et al. (1975) found a 30 per cent mortality in 21 patients undergoing coronary bypass surgery and valve replacement ( 19 aortic and 2 mitral), but Quinlan et al. (1975) attributed 8 of 16 hospital deaths to unoperated coronary disease. In the series reported here 18 patients underwent aortic replacement alone, with a mortality of 5.3 per cent. Though the coronary circulation of these patients was not assessed we agree with Barnhorst et al. (1974) that it has yet to be shown that additional coronary surgery in elderly patients will reduce operative mortality or prolong survival.

Neurological damage from cardiopulmonary bypass does not appear to be a major hazard in this age group. Quinlan et al. (1975) reported 1 patient who had a hemiplegia after femoro-femoral bypass for a thoracic aortic aneurysm and we report 1 patient with persistent impairment of short-term memory and associated depression after uncomplicated aortic valve replacement. Postoperative confusional states were not common or persistent. The incidence of late emboli was low. The report from the Mayo Clinic (Barnhorst et al., 1974) was exceptional in that 4 deaths in 300 patients were the result of cerebrovascular complications and a high incidence of additional unspecified 'cerebrovascular complications' was noted. In no series did long-term anticoagulation produce problems, with the possible exception of 1 patient who died from a subdural haematoma after an accidental fall (Austen et al., 1970).

Elective cardiac surgery in patients over 70 is only justified if it can be shown to reduce disabling symptoms or to increase life expectancy. In this report 81 per cent of operative survivors were alive at a mean follow-up period of 38.6 months. Before operation 96 per cent were limited by cardiac symptoms to functional class 3 or 4 . Of late survivors 90.5 per cent were in functional class 1 or $2 ; 43$ per cent did not require any antifailure therapy, and only 29 per cent required both digoxin and diuretics. In many patients this improvement represented the difference between dependence and independence. The report shows that the results of elective cardiac surgery in severely disabled patients over the age of 70 who are biologically young and have good left ventricular function are comparable to those for patients over 60 . The increased risk of emergency cardiac surgery in patients over 70 is emphasised.

We thank our colleagues at this and other hospitals for permission to include their patients.

\section{References}

Ashor, G. W., Meyer, B. W., Lindesmith, G. G., Stiles, Q. R., Walker, G. H., and Tucker, B. L. (1973). Coronary artery disease-surgery in patients 65 years of age and older. Archives of Surgery, 107, 30-33.

Austen, W. G., DeSanctis, R. W., Buckley, M. J., Mundth, E. D., and Scannell, J. G. (1970). Surgical management of aortic valve disease in the elderly. Fournal of the American Medical Association, 211, 624-626.

Barnhorst, D. A., Giuliani, E. R., Pluth, J. R., Danielson, G. K., Wallace, R. B., and McGoon, D. C. (1974). Open heart surgery in patients more than 65 years old. Annals of Thoracic Surgery, 18, 81-90.

British Medical fournal (1976). Editorial. A policy of despair. 1, 787-788.

Frank, S., and Ross, J., Jr. (1967). Natural history of severe acquired valvular aortic stenosis (abstract). American fournal of Cardiology, 19, 128-129.

Guthrie, R. B., Spellberg, R. D., Benedict, J. S., and Buhl, T. L. (1972). Open heart valve surgery in patients 65 and older. Archives of Surgery, 105, 42-43.

Meyer, J., Wukasch, D. C., Seybold-Epting, W., Chiariello, L., Reul, G. J., Jr., Sandiford, F. M., Hallman, G. L., and Cooley, D. A. (1975). Coronary artery bypass in patients over 70 years of age; indications and results. American fournal of Cardiology, 36, 342-345.

New York Heart Association, Criteria Committee (1964). Disease of the Heart and Blood Vessels, Nomenclature and Criteria for Diagnosis, 6th edn, p. 114. Little, Brown, Boston; Churchill, London.

Oh, W., Hickman, R., Emanuel, R., McDonald, L., Somerville, J., Ross, D., Ross, K., and Gonzalez-Lavin, L. (1973). Heart valve surgery in 114 patients over the age of 60. British Heart fournal, 35, 174-180.

Quinlan, R., Cohn, L. H., and Collins, J J., Jr. (1975). Determinants of survival following cardiac operations in elderly patients. Chest, 68, 498-500.

Ross, J., Jr., and Braunwald, E. (1968). Aortic stenosis. Circulation, 37 and 38, Suppl. V, 61-67.

Requests for reprints to Dr R. Canepa-Anson, National Heart Hospital, Westmoreland Street, London W1M 8BA. 